\title{
A viagem de Ercole Luigi Morselli (1904) à América Latina. Do mito de Ulissea à reescrita do mito: Orion (1910) e Glauco (1919)
}

\author{
Ercole Luigi Morselli's journey (1904) to \\ South America. From and to Ulysses' myth: \\ Orione (1910) e Glauco (1919)
}

Walter Zidaric*

\begin{abstract}
Resumo: O jovem Ercole Luigi Morselli (1882-1921), futuro autor promissor e dramaturgo de sucesso, realiza uma viagem transoceânica rocambolesca por mar, que dura um ano, do verão de 1903 ao outono de 1904. A viagem surge de várias exigências, entre as quais uma manifesta intolerância diante das regras e ensinamentos tradicionais, por parte de um espírito livre e rebelde, animado por grandes veleidades artísticas. O desejo de um "outro lugar" surge da necessidade de distanciar-se provisoriamente da "Madre", termo para entender-se no duplo sentido: pátria - terra das letras e da cultura na qual sonha de afirmar-se com seu futuro ofício de escritor - e de geratriz, isto é, sua mãe, Anna Celli, para poder enfim emancipar-se e "crescer" como homem e como artista, ainda que mantendo, através da correspondência, uma forte ligação com ambos. Entre raríssimos artistas da sua geração, Morselli é um dos que realizou viagem semelhante. Desta experiência fundamental, pode-se traçar uma espécie de itinerário artístico e pessoal do artista, através da correspondência enviada à mãe, na qual aparecem os primeiros claros sinais da sua ambição de artista e dos seus futuros trabalhos.
\end{abstract}

Palavras-chave: Ercole Luigi Morselli. Teatro e literatura no século XIX. Mito. Viagem.

Abstract: The Young Ercole Luigi Morselli (1882-1921), soon to become a recognized author and successful playwright, made a transoceanic and adventurous journey which lasted a year, from summer of 1903 to the autumn of 1904. His decision to travel stemmed mainly from his free spirit's rebellion against the rules and traditional approaches to Art that he thought stifled his artistic ambitions. His desire to go someplace else came from the need to distance himself from both

* Professor associado à Universidade de Nantes, diretor do Departamento de Italiano, ensina literatura e história da civilização italiana e russa. Especialista em ópera e em suas relações com a história e a sociedade, em particular nos anos 1800 e nos primeiros de 1900. 
his Motherland - a land of Culture and Literature where he hoped one day to be recognized as a writer - and his own mother, Anna Celli, so that he could emancipate himself and grow as a man and artist, although he maintained a connection with both by way of letter writing. Morselli is one of the very few artists of his own time to make a similar journey and from this correspondence it is possible to trace a sort of artistic and personal itinerary in which we can identify the first clear signs of his artistic ambition and future projects.

Keywords: Morselli. Nineteenth-Century Italian theater and literature. Myth. Journey.

O jovem Ercole Luigi Morselli (1882-1921)1, futuro autor e dramaturgo de sucesso, morto precocemente no início dos anos 20, realizou uma rocambolesca viagem transoceânica durante um ano, tendo partido em 1903 e retornado em 1904, na companhia de Federico Valerio Ratti (1877-1941)². A viagem decorre de várias exigências, dentre as quais uma manifesta intolerância diante das normas e preceitos tradicionais. Com dificuldade Morselli terminara o liceu em Florença e nunca terminará a universidade, depois de ter realizado a matrícula primeiro em Medicina e depois em Letras. Na realidade será um perfeito autodidata, um espírito livre e rebelde, animado por grandes veleidades artísticas. Todavia, o jovem tem também uma saúde debilitada, que o conduzirá prematuramente ao túmulo. O desejo de um "outro lugar", outras praias, outro clima, nasce também da profunda necessidade de separar-se provisoriamente da "Madre", termo para entender-se no duplo sentido: - pátria-terra mãe, terra das Letras e da Cultura, em que Morselli sonha afirmar-se com sua futura profissão de escritor; e de geratriz, isto é, de sua mãe, Anna Celli, para poder enfim emancipar-se e "crescer" como homem e como artista ainda que mantendo, através da correspondência, uma forte ligação com ambas.

1 E.L. Morselli nasce em Pesaro mas se transfere muito jovem com sua família para Florença. Orfão de pai com 13 anos e filho único de uma jovem mãe, para ela permanecerá objeto de veneração por toda a vida. Faz amizade em Florença com Giovanni Papini, com quem estuda no liceo, com Giuseppe Prezzolini e Alfredo Mori;em 12 de abril de 1900 os quatro amigos construíram uma espécie de seita secreta assinando a 'Proclamação dos espíritos livres', tipo de evangelho ideológico-ético-comportamental” (V. Bertoloni Meli, L. Ferrati, 1993, p. 24). Devo aqui agradecer a direção da Biblioteca Oliveriana di Pesaro, que me permitiu acesso aos arquivos e onde é custodiado o Fundo Ercole Luigi Morselil que contém, entre outras coisas, muitos documentos inéditos; um especial e caloroso agradecimento à Dra. Lucia Ferrati que me orientou a pesquisa com extrema gentileza, simpatia e profissionalismo.

2 Florentino, Ratti é dramaturgo, literato, jornalista; os seus escritos, com frequência inéditos, são também conservados na Biblioteca Oliveriana di Pesaro. 
Como sublinhou Alberto Pellegrino:

Morselli reflete as inquietudes de uma geração de artistas que concebiam a vida como uma "gloriosa corrida pelo mundo"; ele carrega consigo um impulso para construir uma "vida inimitável" diversa do modelo dannunziano, perseguida como sublimação do sofrimento físico e espiritual, como instrumento catártico necessário para realizar um sonho de grandeza e de pureza. (A. Pellegrino, 2000, p. 97-98).

Morselli è um dos raríssismos artistas da sua geração a realizar uma viagem semelhante e, desta experiência fundamental, cheia de inumeráveis peripécias, procurarei traços do seu itinerário artístico e pessoal, através da correspondência enviada à sua mãe, na qual aparecem os primeiros e claros sinais de ambição artística e dos seus futuros trabalhos. Todavia, os temas fundamentais da viagem e do mar, presentes na escrita morselliana, num primeiro momento se concretizam com a aventura transoceânica de 1903-1904, reaparecem em várias obras e, em particular, nos dramas teatrais inspirados em dois mitos gregos, Orion e Glauco, espécie de reescrita com chave moderna do mito que vai inaugurar a sua fama de dramaturgo.

A viagem torna-se realidade em julho de 1903, quando Morselli escreve à sua mãe que ele e Ratti finalmente fecharam

[...] um contrato com o armador Bertolotti di Camogli pelo qual nós somos aceitos na tripulação do seu navio de três mastros: "Angela" que partirá domingo de noite para uma esplêndida viagem direto à Colônia do Cabo, na mais extrema ponta da África Meridional, carregado de tijolos, madeira, ferro e outros materiais de construção. Como não temos nenhum título como marinheiros, fomos arrolados como "marinheiros de reforço" nominalmente, mas somos obrigados a sermos úteis não só com as mãos, mas nas contas e nos cálculos; nominalmente fomos aceitos gratuitamente, mas pagamos qualquer coisa para termos o mesmo tratamento do capitão porque vimos a bordo uma grande quantidade de cebolas e nos disseram que devíamos passar todas pelo corpo dos marinheiros e isto, confesso a covardia, fez lacrimejar. Para este tratamento especial que é simples mas bom, pagamos um franco por dia cada um. (E.L. Morselli, 31.7.1903, ms. inédito. B.O., Fondo Morselli, Ep. c. 2, fasc. 1, n. 11).

Inicialmente o destino final parece ser a África do Sul, ainda se surge, como expediente, a possibilidade de prosseguir para a América do 
Norte; todavia, logo fica evidente a forte ligação afetiva com sua mãe, a quem ele deve tranquilizar e persuadir ao mesmo tempo, visto que será obrigado a recorrer a ela constantemente para financiar a própria viagem. Acaba por reduzi-la à pobreza, depois de fazê-la dissipar a herança paterna com seus constantes pedidos, aos quais ela não se negará jamais a atender, talvez esperançosa da dupla cura do filho, isto é, física e espiritual. Ele escreve:

Estarás pelo menos três meses sem alguma notícia minha, mas pensa que cada noite te escreverei alguma linha, mesmo sabendo que não poderei enviá-la de imediato, depois enviarei toda a correspondência de Capetowen [sic]. Fica alegre e não tenhas medo por mim e por aquilo que farei apenas chegando lá. Pensei muito bem e por isso fiz o acordo com o armador e com o capitão no sentido de, caso desejarmos, podemos deixar o navio em Cap e nos estabelecermos em terra, se encontrarmos nisso conveniência; quem sabe, são tantas as circunstâncias e não é por nada que o chamaram Cabo da Boa Esperança!? Na pior das hipóteses, continuaremos a viagem no "Angela", talvez com um pequeno pagamento, se os nossos serviços forem úteis, e andaremos a Pensacola, na Nova Escócia (América do Norte). Depois voltaremos novamente a Gênova e, ao todo, serão 12 meses de navegação, sempre utilíssimos, também se for o caso, não de todo impossível, que me dedique ao mar, porque são necessários 4 anos de navegação, cumpridos antes ou depois do exame para obter o grau de capitão de longo curso. Mas disso teremos tempo para falar. Seja como for, vou sarando ao contato com aquela gente forte e trabalhadora: se não me curo agora, não me curo de verdade! Mas eu espero voltar para ti muito melhor ${ }^{3}$ (E.L. Morselli, 31.7.1903, ms. inédito. B.O., Fondo Morselli, Ep. c. 2 , fasc. 1, n. 11).

A viagem à América Latina, não prevista no início, surge de uma oportunidade in loco que Morselli e Ratti aproveitam sem hesitar, também por causa da profunda impaciência que se desenvolveu diante da vida e da situação da África do Sul, como se percebe dos desabafos epistolares com sua mãe:

é uma coisa verdadeiramente desesperada viver aqui e nas outras cidades da infeliz colônia, da qual dizem coisas terríveis. [...] Com uma esterlina aqui se faz muito menos que com uma lira na bela Itália: se comem pratos verdadeiramente repelentes e gasta-se cinco

3 Os grifos são de Morselli. 
shillings: num país extra-rico de frutas, mas que faz a mais nojenta exportação, os ingleses podem fazer pagar por uma pêra três ou quatro pence ( 0,45$)$, uma couve-flor um shilling $(£ 1,25)[\ldots]$ além do mais, as ruas são lotadas de certos autômatos com elmos brancos chamados policemann [sic] que têm a incumbência de dar o maior aborrecimento possível aos passantes Ah! Cara liberdade da Itália! (E.L. Morselli. 12.11.1903, ms., inédito. B.O., Fondo Morselli, Ep. c 2, fasci. 1, p. 63).

Todavia, sem perder de vista as próprias ambições artísticas, ele não esquece de confortar sua mãe, fazendo com que participe dos seus desejos recônditos de glória:

Se não verdejasse ainda a maior esperança do meu coração: aquela de ver um dia teu rosto esplendoroso de alegria, ouvindo elogios à minha arte, acredita também que subiria no primeiro navio postal que encontrasse no Cabo e voltaria para abraçar-te logo... Espera portanto com paciência e sonha, como eu, com uma paz não distante nas nossas almas (E.L. Morselli, 10.10.1903, 1986, p. 14).

Um reflexo de tal relação entre mãe e filho me parece registrado em Orion, ainda que encenado nos termos de pai e filho através dos personagens de Ireo, em perene espera do seu filho Orion e que não deseja outra coisa além da companhia deste último, e do mesmo Orion, jovem irrequieto em constante movimento, à procura de novas aventuras. Todavia, em Orion aparece também o motivo da busca pela fama que aspira Morselli, à época da sua viagem:

- Ireo: Oh! sábio Matusio!... Não amo a minha sorte porque me faz padecer e chorar!..Daria tudo aquilo que me resta de vida para que o meu Orion deixasse de perseguir tigres, mulheres e serpentes... e vivesse aqui pacificamente, com essa pouca coisa que, devagar e com tanta fadiga, coloquei à parte para ele...

- Matusio: Louco! Louco Mil vezes louco!... E a Fama?... não sabes o que vale a Fama? Não sabes quanto sofrimento custa uma única carícia sua?... Tu a tens diante, cego? E não a vês! $\mathrm{O}$ teu nome andará através do futuro com aquele do grande Orion!... Ah! Quantos envelhecem se arrastando de gatinhas, sem encontrar sobre a terra suja qualquer miserável segredo caído aos avarentos imortais, não invejarão a tua rara sorte, velho!...). (Orione, I, 3).

Na carta de 12 de novembro de 1903, Luigi refere-se pela primeira vez à viagem a América do Sul: 
De todo modo, estudamos aqui a imigração italiana com paixão e a estudaremos ainda por alguns dias, mas na primeira ocasião será preciso escapar à América do Sul, a Buenos Aires, onde já estamos seguros de encontrar trabalho remunerado junto a um jornal italiano de lá (E.L. Morselli, Lettera alla madre Anna Celli, Capetown, 12.11.1903, 1986, p. 14).

A oportunidade de uma viagem à Argentina surge justamente na África do Sul, uma vez travado conhecimento com um certo Mondego, agente plenipotenciário, como narra na carta de Capetown, em 17 de novembro de 1903, que cito inteira porque inédita:

Desculpa-me cara Mamma, mas esta é uma carta de negócios.

Espero que o meu telegrama não tenha te amedrontado, mas acredito que, pelo contrário, passado o primeiro espanto, terás pensado que isso era uma consequência natural da minha inexperiência e falta de consideração, que me haviam aconselhado a partir para um país pouco hospitaleiro, com uma provisão tão mísera de dinheiro que indignaria qualquer pedreiro ou carpinteiro, país cheio de negócios e privado de qualquer vida intelectual, onde as esterlinas valem tanto quanto as liras na Itália. De resto, nesta horrível cidade, da qual nunca direi mal o suficiente, tanto eu quanto meu amigo encontramos uma verdadeira fortuna.

Não sei se te disse que, entre os italianos que tomaram parte no banquete oferecido pelo Sr. Nannucci, havia um tal Mondego, agente plenipotenciário de duas ou três sociedades industriais da Argentina, com quem falamos muito da dolorosa situação da emigração italiana aqui, admirados porque ninguém pensa em impedir que tantos desgraçados, atraídos por salários nominalmente altos, deixem as boas pagas de Buenos Aires, que é uma segunda Itália, onde se vive com pouco, para vir aqui morrer de fome.

Ele muito aprovou o que dissemos, e ontem esperávamos que nos viesse encontrar a bordo da nossa Angela, onde nos refugiamos para comer batatas novas, para salvar o pouco dinheiro que restou e pensar em paz no modo de irmos à Argentina. Veio e nos ofereceu a possibilidade de irmos nos estabelecer em Buenos Aires, ainda que provisoriamente, (paga a viagem de primeira classe e nós já fizemos reservas com o próximo vapor que partirá no dia 20 ou 22 deste mês). Naquele país, por seu intermédio, estarão abertas as portas da Prensa e da Patria degli italiani e aquilo que escreveremos ou diremos sobre o tema acima mencionado (emigração), será bem retribuído por aqueles industriais que ele representa e que sofrem grave dano por esta fuga louca em direção das hipotéticas minas de ouro e de diamantes. 
É a primeira vez que me surge a ocasião de dar minha opinião e de ser pago para dizê-la, por isso recebi esta oportunidade com entusiasmo. Uma vez assim rompido o gelo, podemos ter esperança de fazer qualquer coisa naquele país com a nossa arte. Mas essa nova orientação das coisas impõe uma vida que não seja miserável nos primeiros dias da nossa chegada lá, antes que possamos trabalhar e sermos pagos porque, de ativo, o único que temos são as passagens para a viagem. Por esta razão (e para ter também um pequeno fundo reposto na minha bolsa para qualquer eventualidade, sendo muito imprudente permanecer sem dinheiro num país assim distante) te telegrafei antes e acrescento agora uma nota com a lista de objetos que me serão muito necessários e que terás cuidado de me enviar a Buenos Aires.

Para enviar-me as 40 esterlinas que te pedi, certamente haverás de subtrair mais mil liras do pequeno capital depositado na Cassa di Risparmio, mas tu não deves, de nenhum modo, sofrer por essa nova manumissão porque, vendendo o quadro, poderás cobrir o vazio com mais do que as 5000 liras. Também poderás fazer o mesmo com qualquer inesperada fortuna vinda do "Signore di Palermo" e te serei grato. De outra parte, faz de modo que, da venda dos campos, venha aquilo de que tens necessidade: estamos entendidos! $\mathrm{Eu}$ acredito que possa aplicar com bom fruto o dinheiro que te pedi e tenho muitas razões para assim esperar: espera também tu, tanto melhor me irão as coisas, tanto mais cedo te faço uma visita... em carne e osso, porque bem sei que não sou tipo que pode estar muito tempo longe de ti e da Itália. Outro dia um carpinteiro de Buenos Aires, falava de Roma que não vê há 13 anos; comecei a chorar e não parei por meia hora. Mas basta: esta é uma carta de negócios, disse. E direi portanto que o cônsul italiano em La Plata é primo de Ratti que, por sua vez, junto a ele é muito bem recomendado. Como de Buenos Aires à La Plata são três horas de trem, não deixaremos de aproveitar esta circunstância favorável para fazer conferências e para ingressar nos jornais de lá. Como vês, são todas essas belas coisas e eu vou sonhando com a felicidade de voltar logo à Itália com um nome estimado e conhecido naquela espécie de colônia italiana, para poder ser lido e avaliado pelos italianos da Itália que têm a mania de não querer saber de autores totalmente ignorados mas que, de outra parte, são os únicos juízes dignos de consideração. E de início, os sonhos! É melhor que te diga adeus.

Afetuosamente o filho

Gigi (E.L. Morselli, 17.11.1903, Ms., inedito.

B.O., Fondo Morselli, Ep. c 2, fasc. 1, n. 16) 
No mês seguinte, como aparece na carta de 30 de dezembro de 1903, também inédita, o projeto argentino se acerta:

\section{Carissima Mamma,}

Finalmente parece que em 15 de janeiro finalmente partiremos para Buenos Aires: o vapor Harmonides deve ainda chegar de Londres, mas a partida é segura e poderá atrasar no máximo um dia, sendo já anunciada nos jornais daqui. É uma verdadeira sorte esta partida porque, justo no final desta semana, o "Angela", do qual te escrevo, tendo terminado de descarregar partirá para Barbados nas Antilhas. Não podes acreditar quanto tédio e quanta despesa teríamos se permanecêssemos somente mais alguns dias na cidade, deixando nossas coisas no depósito da alfândega, por causa das nossas armas que fazem tremer (somente por vê-las), estes caranguejos de consciência suja.

Nestes poucos dias que passei no país inglês, pude acumular uma tal quantidade de observações sobre os homens e sobre coisas ruins que jurei ódio eterno àquela raça de velhacos bêbados e muito ignorantes; todo mal que poderei fazer a eles com a caneta ou com qualquer outra coisa será preciso que o faça. Entretanto, dois boeres com quem falei em um bar me disseram que no máximo em três meses ouviremos falar deles. Tomara!

Outro dia fui ao parque de Cecil Rodes em Rondebosch, vi um grande leão presenteado por Kruger, quando o napoleãozinho da África do Sul girava em torno aos seus pés, farejando sobre os pastos verdejantes o cheiro acre do ouro. Aquele leão rugia com tanta dor, e tantas coisas me fazia pensar o seu rugido, que chorei. Esta erva que te envio colhi junto à sua jaula. Aquela folha prateada nasce na parte mais alta da encosta do monte e a colhi ontem na minha segunda subida sobre o Pico do Diabo (Devilis Peak) com o preparador naturalista Bonomi, do Museu da África do Sul, um milanês simpaticíssimo que ainda não foi persuadido que aqui se fala inglês, e interpela todos os brancos e negros em italiano. Por amor à verdade é preciso que se diga que, de todos os italianos, ricos e pobres, que nos festejaram nos primeiros dias, somente com dois mantemos boas relações: o preparador Bonomi e o seu cunhado, marceneiro de vagões na ferrovia do estado, duas modestíssimas mas dignas pessoas, que vivem numa casinha em Salt River, junto aos quais passamos três domingos verdadeiramente bem, com um pouco de canto, violão e muita cerveja. Com um mestre de esgrima, um engenheiro (que tem contrato para pavimentar estradas com granito) e com alguns outros, temos uma relação indiferente. Entre nós e um certo Hetlinger, judeu genovês que faz negócios de navegação, um inteligentíssimo sem-vergonha, há uma relação de recíproco 
interesse. (De Mondego não falo porque partiu para Londres com o último navio postal, depois de nos haver deixado um monte de apresentações para Buenos Aires, além dos bilhetes de passagem). Mas com outros, entre os quais o engenheiro Petriccioli, de Lerici, que agora está em Johannesburg, empregado na companhia de ouro como químico, que até a sua partida parecia nosso amigo, e com o tintureiro Nannucci, rompemos absolutamente. Basta te dizer que ao primeiro retornamos com uma carta de apresentação recebida do seu pai, coronel dos bersaglieri reformado, que mora em Lerici e, ao segundo, enviamos um saco de roupa suja com um bilhete em que dizíamos que lavasse logo e bem: logo a ele que é milionário e não sai de casa sem cartola, imagina! Enviou o seu secretário, o Conde Gessa (vindo aqui correndo de Buenos Aires, num vapor do tempo da guerra) para dizer que não podia lavar as roupas em menos de 15 dias; respondemos que mandaríamos lavar em outra lavanderia. Mas foi tanta a raiva dele que, não podendo desabafar sobre nós, desejou desabafar sobre um seu operário calabrês e o mandou embora do estabelecimento imediatamente, apontando-lhe o revólver ao rosto; mas aquele bom calabrês lhe deu uma porretada e lhe quebrou o nariz, colocando-o na cama por uma semana. É verdade que quando Nannucci era saltimbanco, terá passado por poucas e boas, estando por isso habituado, mas finalmente alguém o tratou da forma que merece. Uma infinidade de vermezinhos que lhe vivem nas costas agora têm de nós um sagrado terror e fogem como o diabo, mas isso pouco importa. Deixemos estes mexericos. Na minha última carta te enviei uma lista das coisas que desejava que me mandasses a Buenos Aires por meio de uma agência (de preferência à rua Tornabuoni, perto de Alinari) em uma caixa que não precisa ser bonita, mas forte; peço ainda que me envies tudo logo que receberes esta. Se te convém, mandes os livros separadamente pelo correio com aquelas outras coisas que estão assinaladas.

Livros Dante - Scartazzini 3 volumes

“ “ - Ediz. Hoepli con rimário (couro marron) gramática latina Schültze “ “ grega,Schenkle

Baudelaire Fleurs du mal

De Musset Nouvelles poésies

(?) - Virgilio - obra edição 1500 piccolo faltam algumas páginas

Se não encontras qualquer livro, chama para ajudar o Prof. Fantoni, Prezzolini, Marangoni (Viale Principe Amedeo 42).

Outras coisas: - Roupa de passeio Maltagliati

- “ “ roupa de sociedade “ “

- “ cinza Pitani 
- Casacão de meia estação

- $\quad$ suspensórios brancos

- abotoaduras de ouro

- 4 camisas brancas ou ao menos duas

- colarinhos e punhos novos

- 2 gravatas pretas estreitas

- Ciroulas de lã fina e suéter listado

- 1 malha de lã fina

- uma caixinha de pó dental

- binóculos de campo.

Acredito ser inútil repetir tudo que te dizia na carta anterior que continha coisas importantes. Se por um estranho acaso não a tiveres recebido, escreve-me avisando para o Consulado Italiano de Buenos Aires e direi tudo.

O quê fazes de bom? O quê faz a avó? Está contigo? Escreve-me uma longa carta para Buenos Aires, não uma meia folhinha como aquela para Capetown que reli cinquenta vezes para que parecesse mais longa.

Como te disse, meu novo endereço é Luigi Morselli Consulado Italiano - Buenos Aires (República Argentina). Cumprimenta por mim o Senhores Fantoni, Molla e os outros conhecidos.

Um beijão do teu Filho

Me dá notícias daquele safado do Cremaschi. (E.L. Morselli, 30.12.1903, ms., inedito. B.O., Fondo Morselli, Ep. c 2, fasc. 1, n. 20).

Além das alusões à viagem para Buenos Aires, o que impressiona nesta carta é a aversão que ele demonstra pelo país sul-africano, com o qual não conseguiu interagir naqueles meses, assim como as difíceis relações com alguns patrícios que resultam bem distantes da imagem estereotipada da calorosa solidariedade entre emigrantes italianos em países estrangeiros distantes. Todavia, graças à ajuda de sua mãe, Morselli prepara meticulosamente a sua chegada a Buenos Aires, tanto do ponto de vista do vestuário, do qual faz lista detalhada, quanto daquele dos livros que lhe serão necessários durante a permanência na Argentina. Se Baudelaire e De Musset, por quem nutria uma verdadeira paixão, tratam-se de verdadeiros e habituais companheiros de viagem, o pedido que faz de Dante e Virgilio, dos seus livros de gramática latina e grega permitem supor, a posteriori, o interesse talvez nascente naquele momento pela cultura antiga e ligada ao mito.

Terminada a aventura sul-africana (nesse meio tempo os dois companheiros de viagem juntaram um pouco de dinheiro, impro- 
visados como pintores e vendendo quadros de paisagens italianas) Morselli e Ratti conseguem finalmente embarcar para a Argentina em 13 de janeiro de 1904, a bordo do Honorius, um vapor da Houston Line e, depois de uma breve escala na ilha Tristão da Cunha, que inspirará um conto a Ratti, chegam em Buenos Aires no dia $1^{\circ}$ de fevereiro. Do navio, Ercole Luigi escreve à sua mãe em 22 de janeiro de 1904:

[...] quando voltar quero te dar certas lições de astronomia que te farão perder a cabeça. Basta te dizer que há três noites durmo vestido (mais que de hábito) para subir cada meia-hora para ver a via da constelação de Orion [...]. (V. Bertoloni Meli, Prefazione, 1919. p. 14).

Aí está germinando o projeto do mito de Orion, alimentado pela viagem, que será o primeiro drama de sucesso do escritor, representado pela primeira vez no Teatro Argentina, de Roma, em 17 de março de 1910, com a companhia de Gualtiero Tumiati.

Morselli e Ratti são dois, entre dois milhões de italianos, que chegam de navio à Argentina entre 1881 e 1914; acomodam-se no Hotel Continental em Buenos Aires, no bairro da Boca, repleto de conterrâneos, visto que naquela cidade residem à época cerca de 100 mil italianos. Na realidade, entre 1830 e o final da década de 1950, são cerca de 3 milhões e meio os italianos que emigram para a Argentina e, como sublinha Fernando Devoto:

Em boa parte daquele período a Argentina foi, para usar uma conhecida expressão de Cristoforo Negri, de 1864,' a “Austrália italiana", isto é, aquele lugar vazio, despovoado, que contava com um milhão de pessoas pela metade do século XIX, e imenso [...] enquanto a outra metade do território, ocupada por índios também eles pouco numerosos, estava sob controle da civilização hispanoamericana. A relação entre aquele número de emigrantes e este vazio demográfico deu lugar a uma experiência singular que não tem comparação. Os italianos eram de fato muito numerosos para não estarem presentes em todos os espaços e em todas as camadas sociais, assim que o processo de inserção na região foi caracterizado por uma complexidade e uma ambiguidade difícil de compreender. Quase tudo na Argentina pode ser relacionado aos italianos, mas não sabemos bem que coisa pode ser especificamente italiano. (F. Devoto, 2002, p. 25). 
As impressões de Morselli são entusiásticas desde o primeiro momento e se chocam literalmente com aquelas deixadas na carta relativa à permanência na África do Sul. Só para dar um exemplo, o fato de que o navio ficou parado pelos serviços sanitários, por um par de dias, no cais do porto, é por ele avaliado numa ótica positiva que se opunha àquela dos anglo-saxões, para os quais "tempo é dinheiro". Na América do Sul, segundo suas primeiras impressões, é concedido o tempo de apreciar a beleza do lugar, como contará depois em La Cornovaglia:

Direi mais: fiquei contentíssimo quando a Sanità do Porto fez esperar por dois dias (se bem que me retardasse o prazer de desembarcar) porque vi logo que, naquela terra latina, não reinava, em todo o pedantismo da palavra e em toda a baixeza da ideia, o famigerado provérbio: Time is money; espinho automático para os ossudos flancos dos homens do norte [...] mas, pelo contrário, olhando por duas noites o Rei Sol descer placidamente entre a festa das nuvens, nas águas voláteis do Prata, qualquer um terá descoberto, num reposteiro esquecido do coração, alguma coisa mais preciosa do que o tempo e a moeda. (E.L. Morselli, ms. inedito, sem data, incompleto. B.O., Fondo Morselli, Bio. C. 2, fasc. 1, n. 41).

Parece assim evidente, neste trecho, o temperamento poético do jovem escritor, não obstante o caráter literário enfim assumido a partir da viagem e, ao mesmo tempo, vem delinear-se com extrema rapidez uma certa afinidade com os sul-americanos.

Já em fins de fevereiro, os dois jovens conseguem uma colaboração com o jornal La Prensa, o mais importante cotidiano argentino que, em 21 de fevereiro estampa uma fotografia e apresenta-lhes ao público nesses termos:

Los senõres Federico Ratti, doctor en filosofía letras y Luis Morselli, estudiante, después de un característico viaje por el Africa del Sur, recorrerán algunas regiones argentinas, sin ninguna misión oficial, pero con espíritu de hombres cultos y sanos propósitos de estudio [...]. Emprendieron una gira inspirada simplemente por la necesidad de vivir mas intensamente algún tiempo en ambientes nuevos, donde hubiese más campo para cosechar ensenãnzas y inspiraciones robustas [...]. Más poetas quizás que sociólogos, y sobre todo, saturados del espíritu artístico de la más artística ciudad italiana, eludieron hasta donde les fué posible los medios de locomoción modernos y sus comodidades, no ya un obsequio de cierta heroicomicidad infantil, sino por instintiva predilección hacia lo que menos artificios tiene en la vida de nuestros tiempos. (La Prensa, Buenos Aires, 21.2.1904, p. 72). 
O anônimo comentarista parece ter apreendido em profundidade o caráter dos dois jovens companheiros de viagem, quando acena para a "heróicomicidade infantil", mesmo manifestando diante deles um certo obséquio "devido" à cidade de Florença e ao país de proveniência, a Itália.

No outro dia, 22 de fevereiro, La Prensa publica um número especial intitulado Il Pellegrino, quatro páginas em grande formato que, em grande parte, apresentam a poesia e a prosa dos dois jovens. Nos contos de Morselli - La baia della morte, Rinaldo e Gaia, Una rondine nell'Atlantico e La caccia agli Albatros - coloridos de valências românticos-simbolistas, é onipresente o tema do mar, como espaço da liberdade absoluta, da viagem e dos mil perigos que essa representa, como também espaço de nostalgia da pátria distante. O número especial do Pellegrino faz grande sucesso e dá uma enorme publicidade aos dois jovens aventureiros; vendem-se 5000 cópias em pouquíssimos dias. Num primeiro momento parece que os italianos estão destinados a uma brilhante carreira de literatos. Assim, a sua viagem, primeiro da Europa à África, e, em seguida à América Latina, começava a colorir-se de tons legendários que ecoavam da primeira página do Pellegrino:

[...] deitados numa dura rede, ouvia na noite profunda o urro das feras perderem-se entre os distantes ecos dos montes da África Austral [...] em poucas semanas, o puma do campo, os condores dos Andes ou as serpentes do Brasil turvariam de novo o seu sono. (Il Pellegrino, p. 1)

Estes tons depois tornar-se-ão deveras míticos, através da escrita dos dramas teatrais de Morselli e do Glauco em particular, quando o herói sofredor pela própria condição humana aspira a evasão e tem um desejo de eternidade:

Glauco (olha em um momento a sua barca balançar; depois se enfurece contra si mesmo:)

Que Netuno me enforque como a um tubarão! Mas porquê?? porquê? porquê?... então não queres mais bem à tua Scilla?... à tua Scilluccia de ouro?... Mas sim! Mas sim! Por todas as estrelas do céu!... E então?! Conserta os buracos da tua rede, louco! Que o peixe não saia rindo às tuas costas!....Mais seguras e mais ganhas. Mais ganhas e mais depressa a esposas! Aquela besta da Forchis, de amor não se importa: o dá a quem lhe pagar melhor. La tua Scilla!... (começa a remendar a rede sentado com as costas na barca, assim que não vê os Tritões que se empenham para tirar do fundo do mar certas cestas repletas de moedas e pedras preciosas.) [...] 


\section{Os Tritões (piscando entre eles com velhacaria:)}

Esta sim é uma boa pesca! Ouves como soa bem?... Pesca de rei! Pesca de herói!... Mas é preciso ir longe! É preciso ousar! Zeucro e Idro não eram pobres pescadores como tu? Agora são poderosos reis. Há ilhas desertas, onde arrogantes dragões guardam fontes de ouro!... Há terras férteis de homens e de colheitas, sujeitas por algum monstro voraz; e os homens choram! E clamam por alguém que os liberte!... Degolar dragões e monstros é fácil. Basta não tremer!

\section{Glauco (levantando-se:)}

Não! não! não! Inútil fechar os ouvidos se o coração grita! Mas que coração! Tenho uma águia enjaulada aqui dentro, que grita e dilacera!...

$[\ldots]$

(movendo-se) Para o inferno a tua rede e o teu arpão, e o nosso ofício porco!... Mas melhor que consertemos a vela, e puxemos o cordame! Façamos aquilo que foi dito tantas vezes. Um bom carregamento de lã tecida... e adiante!...

$[\ldots]$

A vender... a tornar-se um rei!... Veremos!... Mas não terás nojo deste pateta que volta toda a tarde sobre a esteira da manhã? Eu vou. Coloco a proa para a África e vou. [...]. ${ }^{4}$ (E.L. Morselli, 1986, p. 27-30, atto I $(1,2))$

(riscuotendosi:) Para o inferno a tua fiocina e a rede, e il porco ofício nosso!... Mas melhor, consertemos a vela, e aliamo o cordame! Façamos aquilo que foi dito tantas vezes. Um bom carregamento de lã tecida... e via!...

$[\ldots]$

A vender... a tornar-se rei!... Se verá!... Mas não tenha nojo deste pateta voltar toda a tarde sobre a esteira da manhã? Eu vou. Coloco a proa para a África e vou. [...]. (E.L. Morselli, 1986, p. 27-30, atto I $(1,2))$.

Este momento de glória parece galvanizar os dois jovens amigos, decididos, com espírito romântico de aventura e sacrifício, e sobre traços do mítico herói dos dois mundos, a lançarem-se em uma verdadeira guerra entre as fileiras de um comitê garibaldino. Alcançam assim

4 Reprint da edição Fratelli Treves Editori, Milano, 1919. O drama foi apresentado pela primeira vez no Teatro Argentina di Roma em 30 de maio de 1919, com a companhia de Virgilio Talli. 
Montevidéu por navio, junto a outros voluntários e são arrolados no batalhão comandado pelo tenente-coronel Ferrara: Morselli com a divisa de capitão e Ratti com aquela de major. As aventuras uruguaias e o retorno a Buenos Aires serão objeto de uma narrativa detalhada na carta que Ercole Luigi inviará à sua mãe em 12 de abril de 1904, de Rosário, publicada integralmente sul Corriere della Sera de 31 de dezembro de 1930 (E.L. Morselli, 12.4.1904, ms. B.O., Fondo Morselli, Ep. c. 2, fasc. 1, n. 28), em que narra as suas aventuras uruguaias e o retorno a Buenos Aires:

Minha Mãe, tu que estarás contando as horas à espera de qualquer notícia minha, não poderás jamais imaginar como voaram para mim estes dois meses de América. Primeiro todas aquelas atrozes dificuldades financeiras, depois um período todo de glória, de popularidade, de riqueza desde que La Prensa (de que não poderás fazer ideia clara se não quando eu conversar em paz contigo) ocupou-se de nós e todos os jornais fizeram eco, e nós publicamos o jornal que recebeste (do qual vendemos 5000 cópias) e de que decorreu a proposta para a fundação de um jornal italiano, da parte de um senhor que tinha a mania (comum a muitas pessoas) de acreditar-se muito esperto: mas as mil liras não saíram da minha bolsa, como te escrevi do Uruguai. Por demais cansados da viagem, tínhamos a ideia de voltar à Europa, quando percebemos que um Comitê Garibaldino havia tomado a iniciativa de formar uma legião italiana que deveria combater pelos colorados contra os brancos. Em seguida fizemos contato com esses colorados, por mil razões que tu talvez não aprovarias, e como primeira razão aquela de preparar-nos como militares para quando formos tomar Trieste, ignorando todos os tratados comerciais e todas as visitas imperiais.

A querer contar-te tudo o que aconteceu em Montevidéu e na excursão a Salto e San Antonio (onde Garibaldi desbaratou 10.000 brancos com 250 legionários) seria querer demais.

Em breve, em poucos dias, colocaremos para fora da Lgião todos os chefes, $[\ldots]$. Os homens chegavam todos os dias mas, pela escassez de italianos, éramos obrigados a aceitá-los de todas as nacionalidades [...] e esta foi a nossa ruína. Deixamos no comando da legião um ex tenente dos Bersaglieri, em quem desgraçadamente confiávamos [o capitão Ferrara] e fomos cumprir uma perigosa excursão nas redondezas do teatro da guerra, tendo obtido do governo um salvo-conduto que, de resto, foi bem menos útil do que o meu novo revólver que é qualquer coisa de terrível.

Voltando ao nosso bairro em Montevidéu sãos e salvos (eu com uma costela machucada por uma pedrada de um branco e D'Agostino 
com uma facada no braço), encontramos uma terrível revolução porque fora anunciado, pelo Marquês de Ferrara e por novos oficiais uruguaios, que havíamos desmerecido o governo uruguaio e que havíamos sido expulsos da legião com a respectiva ordem do dia. Coisas da América! Os italianos se rebelaram com este anúncio e declararam que era tudo falso e que sempre viriam atrás de nós e nunca atrás deles. Trataram de sair do bairro, enquanto os espanhóis impediam pela: os moços dos brancos assobiavam de fora: um pandemônio! Chegando ao final do incidente, procuramos pacificar e impedimos a intervenção da polícia. Prometemos aos italianos que a legião nos teria como chefes, ou não haveria legião e, neste caso, pensaríamos em reconduzi-los ao seu trabalho em Buenos Aires, ajudando-lhes como fosse possível. Como se havia espalhado o boato de uma rebelião branca na cidade, e havíamos atiçado o ódio de muitos desses brancos, percebemos que o nosso bairro estava em ótima posição para ser assaltado por mar e terra. Assim, depois de ter trancado por astúcia engano, na sua companhia, os espanhóis e os filhos do país de quem desconfiávamos, com nossos italianos fizemos a guarda toda a noite, armados até os dentes. Alguma pedrada alcançou o teto de zinco, um barco tentou aproar no nosso cais, mas prontamente voltou para o largo e a noite passou. No dia seguinte a sorte acudiu: percebemos que, por muitas razões, aquela legião haveria de igualmente acabar e resolvemos eliminála, matando junto as ambições de tantos bandidos que esperavam grandes lucros. Por isso, nós e D'Agostino fomos ao estado maior e, sem mais, solicitamos a dissolução da legião, 500 peças de ouro (2500 liras italianas) para restituir as despesas (eu havia quase terminado as minhas mil) e as viagens de retorno a Buenos Aires para todos os italianos. Tudo isso foi combinado. Então, em duas carroças especiais, acompanhados de um coronel do Estado Maior, percorremos todo o bairro, reunimos todos os homens e anunciamos a dissolução da legião. À nossa chegada triunfal, foi bonito ver o Marquês de Ferrara e os novos oficiais uruguaios saírem furtivamente. Nós e nossos italianos fomos para o porto em meio aos vivas dos brancos e assobios dos colorados. Sob um pôr-dosol de fogo; embarcamos para Buenos Aires. Que bela juventude! Como teria desejado conduzi-la em uma outra terra mais distante de mim e mais perto de ti, para terminar a obra dos heróis vestidos com a sua camisa vermelha! Mas ainda não é tempo e, assim, pela manhã, chegados a Buenos Aires e, depois de distribuído um pequeno soldo entre os soldados, os abandonamos de novo às garras da cidade e ao miserável trabalho com as máquinas: alguns deles possuíam ânimo de heróis e teriam feito qualquer coisa no campo de batalha! Bem, também essa me andou mal. Talvez tenha andado bem para ti, porque recomecei a girar pela Argentina e agora estou 
em Rosário, onde publicamos um outro número único e faremos uma conferência; espero que possamos conseguir algum dinheiro. Nesse meio tempo, há um verdadeiro assédio de gente que deseja fazer fotografias, que quer dados biográficos, e todos os jornais falal de nós e das nossas façanhas, mais ou menos exageradas. A América é assim: mais se inventa mentiras, mais acreditam e o mal é que nós ainda conservamos muitos escrúpulos europeus.

Os cartões-postais assinados por nós são vendidos e as senhoritas fazem uma corrida para obtê-los; de resto, sabes o quanto odeio essas charlatanices e, se não fosse pelo dinheiro para retornar a Europa sem miséria e para libertar-me dessa maldita armadilha da América, onde se ganha mas se gasta de modo bárbaro, na verdade não faria tudo isso.

Enfim, é uma bela escola de vida!

E tu, como estás? Faz tempo que não tenho tuas novas. Se escreveres, escreve sempre ao consulado de Buenos Aires. Os nossos negócios de Castello espero que andem melhor. Fica contente e espera que, de um momento a outro, alguma novidade te dará prazer.

Saúda os nossos conhecidos e pergunta a eles se recebem os cartõespostais que vou enviando de cada país. Adeus. Um grande beijo do teu

Gigi. (E.L. Morselli, 12.4.1904, ms. B.O., Fondo Morselli, Ep. c. 2, fasc. 1, n. 28).

A carta de Rosário merece algumas reflexões. Em primeiro lugar, o cansaço decorrente da permanência sul-americana é para interpretar como aborrecimento pela inação que funciona como impulso para os dois companheiros e os leva a embarcar numa aventura de tons heróicos - mas que assume também aspectos míticos graças à figura de Garibaldi - e que coloca em exibição a sua vontade de lutar no Uruguai, ao lado dos mais fracos, os colorados, contra os brancos colonialistas, liderados pelo general Aparicio Saravia (1855-1904). Os dois jovens são animados pelo senso de justiça e de probidade, mas também por uma atração evidente de caráter romântico-idealista diante da figura do herói, que sentem poderem encarnar quando se arrolam, em 15 de março de 1904, na legião "Garibaldi" e recebem a célebre camisa vermelha (que Morselli levará à Itália como um preciosidade e que hoje está custodiada no pequeno museu da Biblioteca Oliveriana). Entre aventuras reais que logo se transformam em narrativas e fatos legendários, através da mediação entre escrita e memória, os dois voltam a Buenos Aires no fim da guerra. Em seguida à morte imprevista do general Saravia, 
ocorrida em 8 de abril, e procurando desfrutar aquele pouco de fama que ganharam, por exemplo através da venda de cartões autografados. É isso que os leva a viajar através da Argentina para responder aos convites que recebem e para agilizarem uma futura colaboração com os dois maiores cotidianos do país, que todavia não acontecerá. Assim, entre 10 de abril e 6 de maio, visitam Rosário de Santa Fé e depois estão novamente em Buenos Aires, imersos no mundanismo, em concertos, conferências, contatos com poetisas locais, entre as quais Manuela y Zapata, María de Las Mercedes Carvajal e Angela de Carvajal Marquéz, além de acompanharem a re-edição do Pellegrino. O período revelase particularmente dispendioso e Morselli acaba por esbanjar todo o seu dinheiro, inclusive aquele enviado pela mãe; reaparece assim a saudade e o desejo de retorno: "O que é mais belo no mundo do que o retorno! E eu que parti para retornar, pensa como estou pouco contente." (E.L. Morselli, 22.5.1904, ms., inedito. B.O., Fondo Morselli, Ep. c. 2, fasc. 1, n. 32).

Sem ter feito fortuna e sem nenhuma empresa heróica no horizonte, Morselli e Ratti retornam, a partir em 9 de junho, no navio inglês Meleda $M$., com destino a Falmouth, tendo no comando o capitão genovês Moglia. Após dois meses, chegam à Inglaterra.

Depois de ter arruinado sua mãe, a ela escreverá uma longa carta da Inglaterra, para prepará-la ao seu retorno e para mostrar a ela e a si mesmo que esta viagem foi parte fundamental de um itinerário espiritual e educativo de iniciação à futura carreira de artista e de literato. Dessa viagem, segundo ele, sua mãe deve estar orgulhosa:

O meu instinto artístico superou maravilhosamente a prova de fogo que desejei infligir-lhe com esta viagem de mais de um ano através de países de comércio, indústria e meios financeiros: distanciado duramente do lugar onde nasci e das coisas que pareciam indispensáveis à nova vida, lançado no meio do mar, sob o céu tempestuoso na imensidade do Pampa, nas alturas da África austral, enquanto eu, eu mesmo que tanto amava e tanto havia esperado deste viagem, acreditava que enfraquecesse e morresse como uma flor da serra, esquecida embaixo de um plenilúnio sereno, vi, quase contra a minha vontade, essa viagem dar tais frutos que estou seguro, num dia próximo desfrutarei, ao ver-te chorar ao lêlos, $[\ldots]$ Ora tu, certamente impulsionada pelas fábulas de qualquer um, porque o teu belo coração de mãe não pode sonhar uma sorte mais bela do que a fama poética, desde que me levavas ao seio; tu, do dia em que decidi sacrificar tudo, menos aqueles quatro castelos inexpugnáveis que se encontram em torno do meu coração, à grande 
chama que o faz arder, tu acreditaste de perder teu único filho para sempre, como se a morte o houvesse apanhado. [...] Mas depois pensa na nobreza da Arte que escolhi e não penses que os artistas se tornam a cada dia os diretores espirituais do mundo? [...] Não penses que, se chegarei aonde desejo, como estou certo, o nome que me deu meu pai e que é também teu permanecerá vivo, quando eu e tu seremos mortos? Ah! Se meu pai pudesse saber: ele que teve o coração de artista e que talvez, na sua primeira juventude, teria desejado sentir o peito torturado por aquela chama que tortura o meu, ele que se aproximou da Arte sem poder jamais criar, como se alegraria... eu estou certo que sabe de tudo e, vendo com os olhos que lhe deu a morte, está contente comigo.

Tu pensarás: tudo isto vai bem, mas os anos passaram e eu ainda não tive da tua Arte nenhum prazer que compense as infinitas dores que me deu. E é verdade! Muitas mães foram até agora mais afortunadas do que tu. Mas [...] estou certo que os prazeres que gozarás quando estarei contigo serão mil vezes maiores do que aqueles que a minha estúpida piedade te poderia dar agora e tais, que as dores que hoje te parecem imensas se perderão na névoa distante da tua memória; assim eu, filho cruel, desejo que chores o meu pranto por algum tempo ainda.

Que chores o meu pranto [...] desejo e quero porque é a prova maior do teu amor. Mas que chores por tudo aquilo que faço na vida quase como se eu fosse um louco perigoso, isto me provoca uma dor atroz e me ofende e nenhuma ofensa é maior do que aquela que se recebe da mãe.

Se aos olhos dos outros esta minha viagem pareça o maior engano da minha vida não me importa absolutamente nada, mas que penses assim isto não posso suportar; [...]. ${ }^{5}$ (E.L. Morselli, Agosto 1904, ms. B.O., Fondo Morselli, Ep. c. 2, fasc. 1, n. 34).

Retornado à casa em fins de setembro, via Londres e Paris, Morselli dedica-se a escrever como anuncia na carta de Falmouth:

Esta vida distante dos livros, das pinturas, da architetura dos nossos países fortaleceu a minha inventiva e tenho uma tal quantidade de coisas escritas e por escrever que alcancei aquela fé inquebrável no meu futuro, fé que não me pode abandonar e será aquela que me guiará no trabalho assíduo e fatigante que estou por empreender, com uma seriedade e com uma força nem ao menos sonhada antes de hoje. (E.L. Morselli, Agosto 1904, ms. B.O., Fondo Morselli, Ep. c. 2, fasc. 1, n. 34).

5 Publicada su La Tribuna di Roma il 14.3.1931 com o título Dall'epistolario di Ercole Luigi Morselli. Avventure e speranze in terre lontane. 
Nos primeiros dias de dezembro se estabelece em Roma, onde já está Ratti, com o primeiro livro embaixo do braço: Favole per i re d'oggi, que será publicado em 1909, além de outras prosas.

Para concluir, como justamente sublinhou Alberto Pellegrino,"o amor pela viagem e pela aventura consente a Morselli de não fazer propriamente o mito do herói decadente (que o havia atraído na juventude) dedicado a acabar com a própria vida nos cafés e nos prostíbulos, abusando do álcool e das drogas e, contrariamente a D’Annunzio, poeta-vate, ele

Primeiro concebe o motivo da viagem como momento de exploração do mundo e do próprio eu, assim transforma o seu ideal de herói em um anti-herói quando descobre a inutilidade da viagem como "iniciação" heróica: a procura da glória, do poder, da riqueza, da imortalidade perdem o seu valor absoluto, porque à força centrífuga da partida corresponde a força de atração do retorno aos valores da família, da casa, do amor e da fidelidade mesmo depois da morte (Glauco). No interior desta crepuscular epopéia, de sabor pequeno-burguês, caraterizada pela dialética pró-contra a glória e a aventura, emerge a exigência de um personagem que tem a incumbência de contar e depois de externar as empresas do herói, por isso em Morselli (a par de Homero e do mesmo D'Annunzio) nasce a exigência de colocar ao lado do herói a figura do aedo, com o dever de transmitir a gesta como no caso do pastor-músico em Glauco. (A. Pellegrino, 2000, p. 98-99).

No retorno da viagem, como reflexão filosófica sobre a experiência recente, Ercole Luigi escreveu:

Ande pelos intrincados portos dos grandes mercados do mundo e verá que, enquanto os homens carrancudos, decididos a negociar, não olhando para cima, os grandes mastros dos navios ancorados movem lentamente as suas extremidades. Querem dizer que tudo que se faz é em vão: só é verdade aquilo que se sonha. (A. Pellegrino, 2000, p. 102).

Todavia a sua viagem não é em vão e, sobre os traços de Ulisses, ele percorre o caminho do conhecimento de si e de um alhures que termina abrindo-lhe as portas da escrita, da literatura e da arte. Tudo serviu para preparar-lhe à carreira literária, que desejou intensamente. 


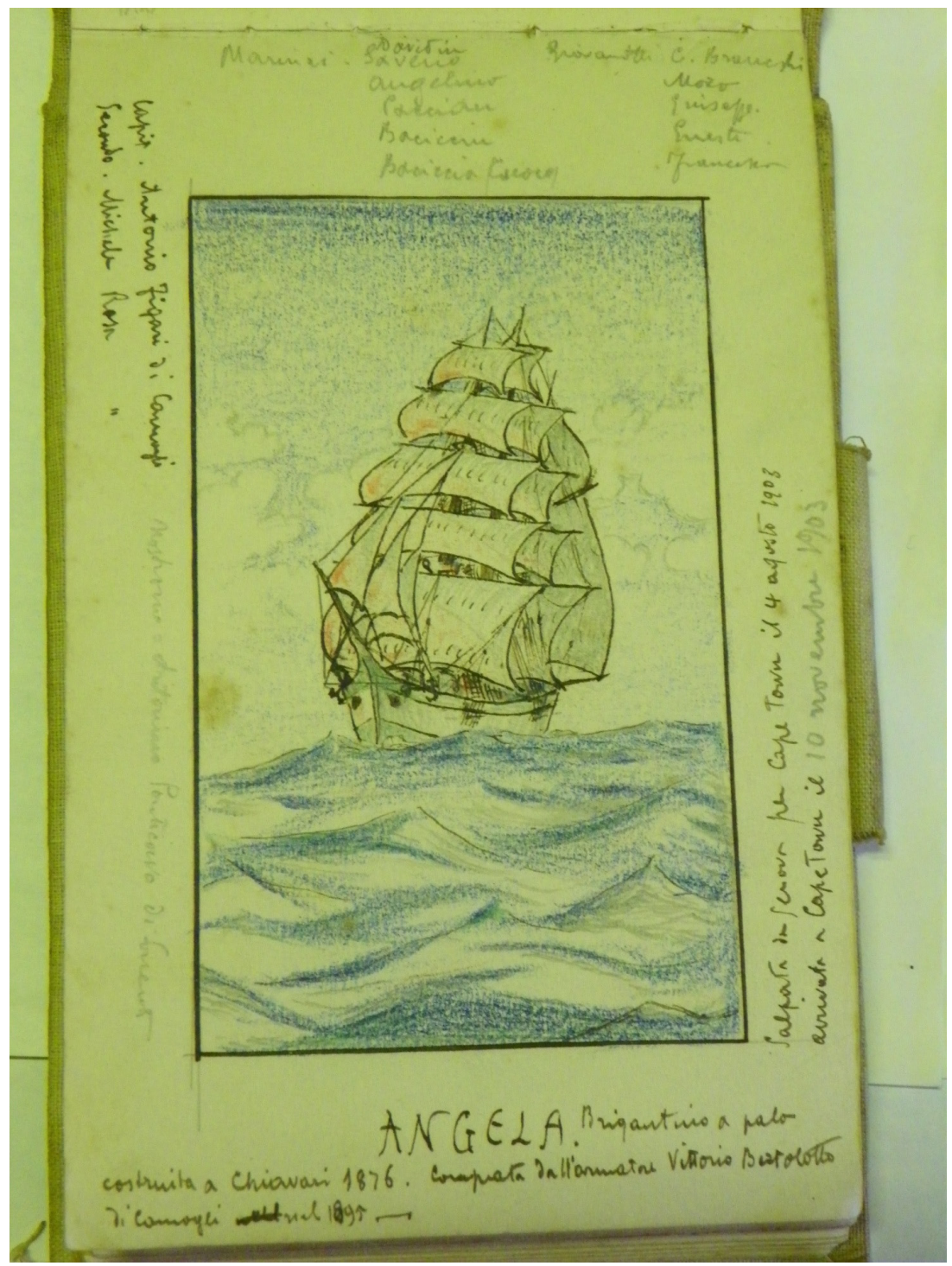

O navio Angela. Desenho assinado e inédito de Morselli, in B.O., Fondo Morselli. 


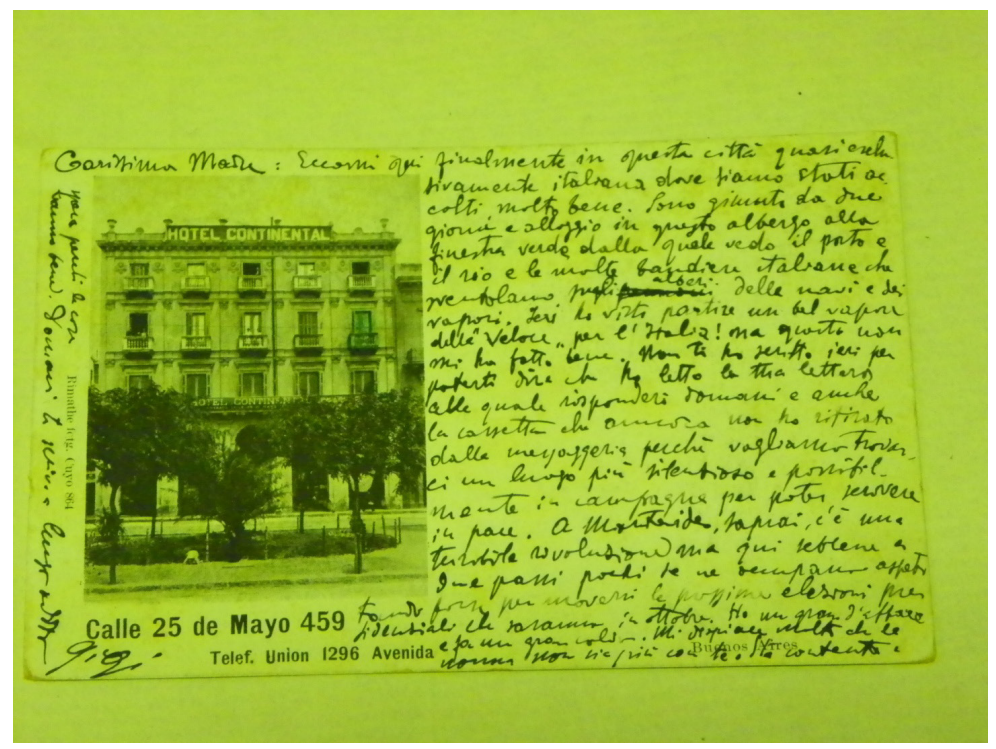

Cartão postal à mãe Anna Celli, Buenos Aires, primeiros dias de janeiro de 1904, ms., inedito, B.O., Fondo Morselli.

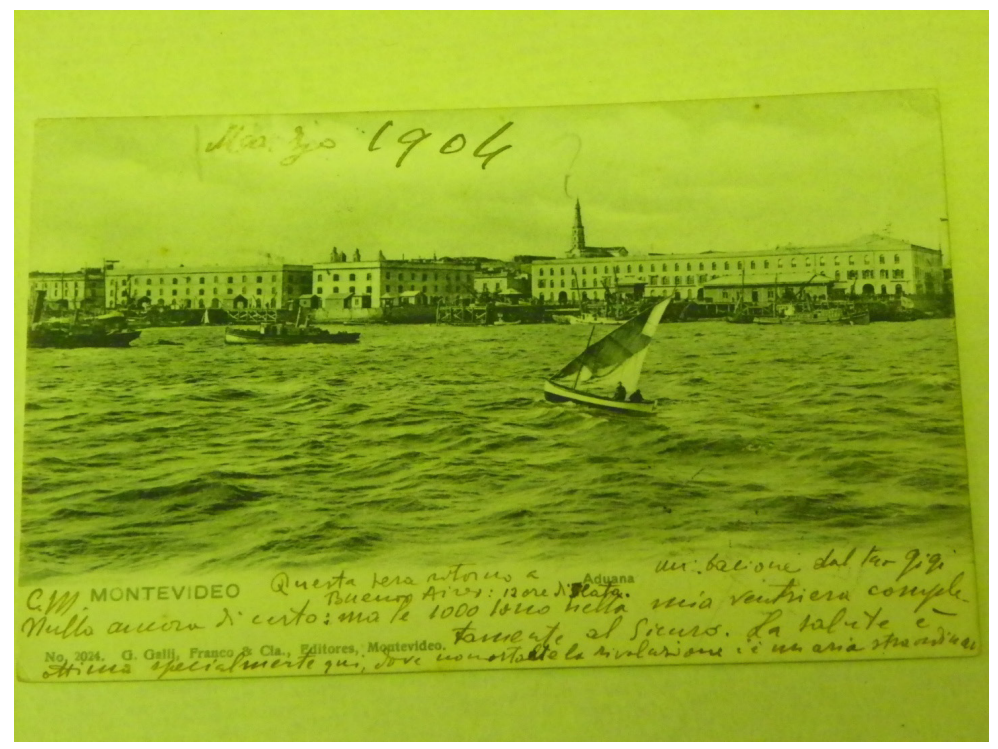

Cartão postal à mãe Anna Celli, Montevidéu, 15.3.1904, ms., inedito, B.O., Fondo Morselli. 


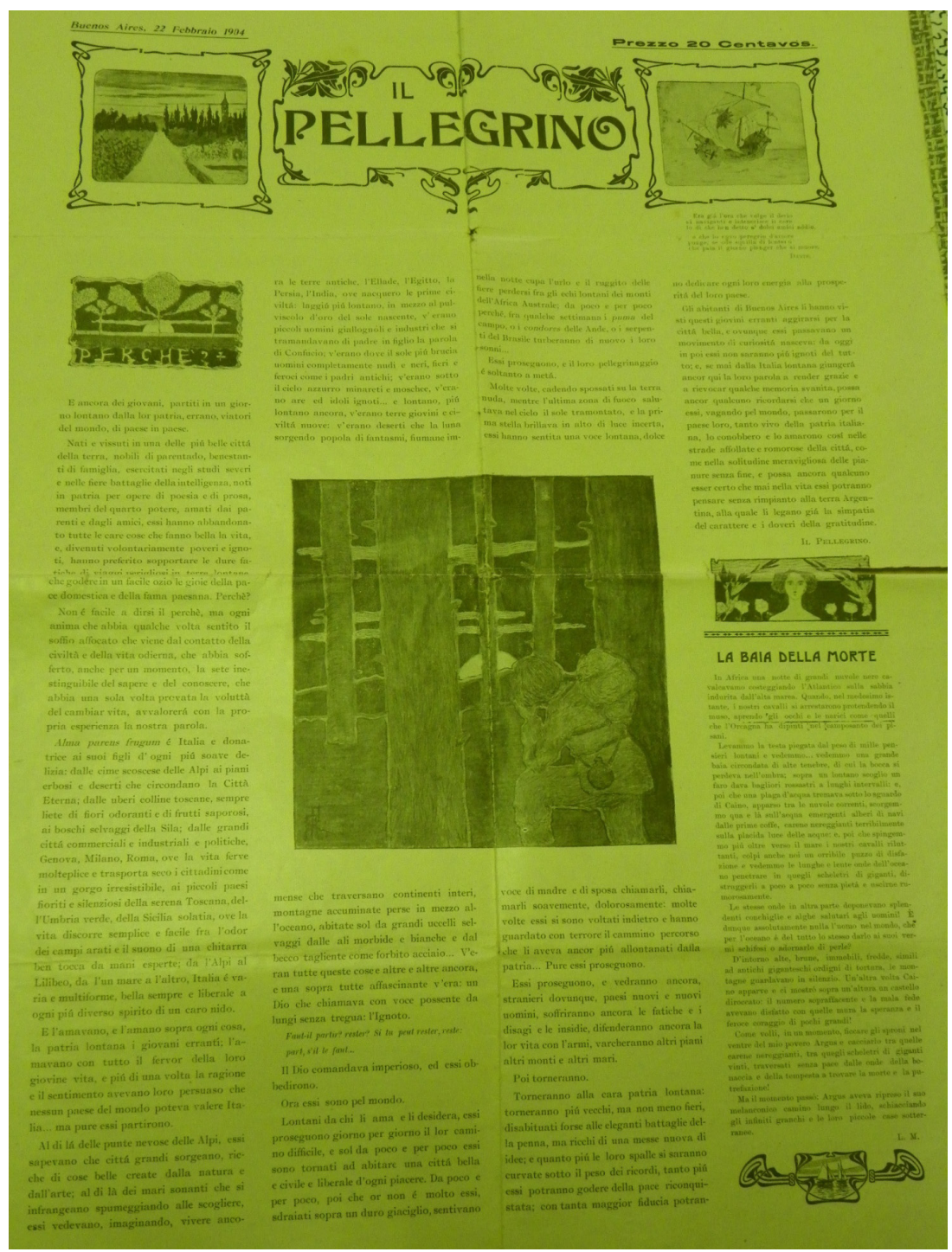

Primeira página do número especial do Pellegrino, Buenos Aires, 22.2.1904.

\section{Referências}

A. Pellegrino, Ercole Luigi Morselli e il teatro del primo Novecento, in Le Marche: La cultura "sommersa" tra Ottocento e Novecento, Atti del Convegno di studi dell'Accademia Georgica di Treia, Treia, 8-9 novembre 1997 - 7 novembre 1998, Macerata, ed. Queen, 2000. 
E.L. Morselli, Cartolina alla madre Anna Celli, Buenos Aires, 22.5.1904, ms., inedito. B.O., Fondo Morselli, Ep. c. 2, fasc. 1, n. 32.

E.L. Morselli, Glauco, a c. di V. Bertolini Meli, Comune di Pesaro,1986, p. 27-30, atto I $(1,2)$ : reprint da edição Fratelli Treves Editori, Milano, 1919.

E.L. Morselli, Glauco, a c. di V. Bertolini Meli, Comune di Pesaro,1986, p. 27-30, atto I $(1,2)$ : reprint da edição Fratelli Treves Editori, Milano, 1919.

E.L. Morselli, La Cornovaglia, ms. inedito, sem data, incompleto. B.O., Fondo Morselli, Bio. C. 2, fasc. 1.

F. Devoto, "In Argentina", Storia dell'emigrazione italiana, Arrivi, a c. di P. Bevilacqua, A. De Clementi e E. Franzina, Roma, Donzelli editore, 2002.

La Prensa, Buenos Aires, 21.2.1904, artigo não assinado, Huéspedes italianos, Un viaje original, cit. in E.L. Morselli, Vita e opera, Firenze, La Nuova Italia, 1993.

V. Bertoloni Meli, L. Ferrati, Ercole Luigi Morselli, Vita e opera, Firenze, La Nuova Italia, 1993.

\section{Fontes:}

E.L. Morselli, Lettera alla madre Anna Celli, 10.10.1903, cit. in V. Bertoloni Meli, "Prefazione", in E.L. Morselli, Orione, a c. di V. Bertolini Meli, Comune di Pesaro, 1986, p. 14: reprint da edição Fratelli Treves Editori, Milano, 1919.

E.L. Morselli, Lettera alla madre Anna Celli, Capetown, 12.11.1903, ms., inédito. B.O., Fondo Morselli, Ep. c 2, fasci. 1, n. 15, cit. in V. Bertoloni Meli, L. Ferrati, Ercole Luigi Morselli, Vita e opera, Firenze, La Nuova Italia, 1993.

E.L. Morselli, Lettera alla madre Anna Celli, Capetown, 12.11.1903, , ms., inédito. B.O., Fondo Morselli, Ep. c 2, fasci. 1, n. 15, cit. in V. Bertoloni Meli, L. Ferrati, Ercole Luigi Morselli, Vita e opera, Firenze, La Nuova Italia, 1993.

E.L. Morselli, Lettera alla madre Anna Celli, Capetown, 17.11.1903, Ms., inedito. B.O., Fondo Morselli, Ep. c 2, fasc. 1.

E.L. Morselli, Lettera alla madre Anna Celli, Falmouth, Agosto 1904, ms. B.O., Fondo Morselli, Ep. c. 2, fasc. 1, n. 34, publicada su La Tribuna di Roma il 14.3.1931 com o título Dall'epistolario di Ercole Luigi Morselli. Avventure e speranze in terre lontane.

E.L. Morselli, Lettera alla madre Anna Celli, Genova, 31.7.1903, ms. inédito. B.O., Fondo Morselli, Ep. c. 2, fasc. 1.

E.L. Morselli, Lettera alla madre Anna Celli, Rosario, 12.4.1904, ms. B.O., Fondo Morselli, Ep. c. 2, fasc. 1, n. 28, publicada no Corriere della Sera em 31.12.1930.

E.L. Morselli, Lettera alla madre Anna Celli, Rosario, 12.4.1904, ms. B.O., Fondo Morselli, Ep. c. 2, fasc. 1, n. 28, pubblicata sul Corriere della Sera il 31.12.1930.

E.L. Morselli, Lettera alla madre Anna Celli, Salt River, 30.12.1903, ms., inedito. B.O., Fondo Morselli, Ep. c 2, fasc. 1. 